\title{
Development of An Examination Authentication Embedded System Based on Fingerprint Approach.
}

\author{
Oyediran Mayowa Oyedepo (Member IAENG) ${ }^{1}$, Wahab Wajeed Bolanle ${ }^{2}$, Elegbede Adedayo Wasiat ${ }^{3}$, Enegbe \\ Toye, Jolie ${ }^{4}$. \\ Bells University of Technology, Ota, Ogun State, Nigeria. \\ 1mayor yoppy02@yahoo.com, , 2 bola4reel2000@yahoo.com, ${ }^{3}$ bimpe24@rocketmail.com, \\ 4joliejols55@gmail.com
}

\begin{abstract}
Security is crucial all around. Access into institutions, examination centers, organizations or even estates ought to be controlled and closely monitored through a verification system. The method of authenticating a student for an examination has an obvious problem such as presentation of fake clearance card, impersonation and so on and the unethical manner associated with the examination is a grim issue that requires the stakeholders in academic area to seek for alternative means of authenticating student for examination, because the manual paper-based clearance process is fundamentally flawed. Sequel to that, a dependable and effective system is designed to tackle the issues of the convectional technique. The system will verify the understudy using fingerprint biometrics technique and generate a report which can serve as an attendance.
\end{abstract}

Indexing terms/Keywords: Fingerprint, Biometrics, Authentication, verification, attendances.

Subject Classification: Embedded System

Type (Method/Approach): Laboratory-Experimental

\section{Introduction}

The world has become a global community of technology today, especially with the computer technology. Due to these technologies we have various ways of securing our information or data. In today's university, verification and authentication of student identity can be easily falsified thus impersonation becomes rampant in lecture hall or examination hall due lack of effective measure in carrying out verification process. The conventional method for verifying student in examination hall is carried out by telling the student to show their identity card and their examination clearance.

Furthermore, the process of managing student attendance in the university can be very stressful when using the conventional method of paper and file system. Every institution presents a standard on how attendance is to be carried out/taken for student in examination halls, laboratory sessions and lecture halls. Using the conventional methods, there are some disadvantages such as monitoring the student attendance which is time consuming, tedious and prone to errors. These paper and file system attendance taking approaches encourage fraud and impersonation during the examination. As the level of security breach increases, the need for highly secured identification and personal verification technology is fast becoming apparent [8].

The aforementioned shortcomings have been an issue so many institutions are battling with over the years, which leads to need of reliable techniques to protect access rights to their existing services or operations. This has caught the interest of researchers to develop/design authentication systems using biometrics approach.

Biometric recognition techniques have emerged as most promising option for securing valuable information or system based on their physiological and behavioral characteristics. Because of the fact that individual's biological traits cannot be forgotten, forged, misplaced or stolen [9]. Individual physiological and behavioral characteristics such as fingerprint, retinas and irises, facial and voice pattern and hand gestures can all be used for authentication purpose.

Fingerprint technique is one of the most popular applications in identification \& verification as it develops a low-cost fast computing system. Applications include accessing buildings or facilities, withdrawing money or using a credit card, gaining contact to electronic information on a local computer or over the internet [3]. Fingerprint has three main advantages over other biometrics techniques [10 7]: 
i. Low cost of deployment (cost effective).

ii. Simple to implement and use.

iii. User must be physically available at the point of identification or verification

This study focused on designing a fingerprint authentication embedded system device for higher institutions in developing countries.

\section{Overview of Related works}

Mohd [12] proposed a class attendance system utilizing RFID for configuration. A dynamic RFID reader was utilized to consequently trigger a tag on the understudy and the contained data, and then checked from a database of understudy data. The advantage of this system is its conveying ability. In other words, the understudies will be required to carry tags around and they may forget and thus marked absent from lecture attended. It is worse if the understudy forgets the tag amid an examination. Another inadequacy of this approach is that it utilized Visual Basic 6.0, which Microsoft was no longer supporting even at the time and furthermore they utilized Microsoft Access database, which is not a venture based database.

Mohammed [11] proposed a Fingerprint attendance system for educational institute. The system could take accurately the attendance of the understudies and evaluate the level of attendance for the understudies automatically and show student attendance on the web, as well as send reports by email to their guardians. The system consisted of the fingerprint reader, control unit, and PC in order to make the system flexible and suitable.

[7] proposed a wireless attendance management system based on iris recognition. The system utilized a wireless attendance management system that verifies by using the iris of a person. The system utilizes an offline iris recognition management system that can complete all the procedures including capturing the image of iris recognition, extracting minutiae, storing and matching.

Olaniyi [4] developed a Lecture attendance system using radio frequency identification and facial recognition. The system manages the student lecture attendance using a windows application system, the developed RFID and facial recognition based attendance model. The facial recognition system would not be able to verify accurately when there is a poor lighting resolution and the system can be affected by poor network.

Hamid [9] proposed a RFID-based systematic student attendance management system to track understudies utilizing the RFID system. The proposed system installed integrated radio frequency circuits in understudy identity card. The system developed also gives real time access to attendance reports by means of the web. The utilization of embedded chips on identity card guarantees that every understudy is authenticated and marked for attendance securely and genuinely. The system is thus not suitable for implementation in remote areas where there is constrained access to the web. Additionally, the cost of network access is high therefore increasing the cost implementation.

Kokumo [6] proposed the use of fingerprint to solve attendance monitoring issues. The fingerprint authentication technique was achieved using extraction of the understudy fingerprint. The proposed system achieved the aim of monitoring the attendance but lacks the inclusion of a report generation and audit trail system.

Due to the inefficiency of the conventional means of taking attendance in the higher institution, a more secured and accurate biometric based model is needed to be formulated and implemented.

\section{Materials and Methods}

The fingerprint biometric attendance system is a system that allows the student scan their finger in order to gain access into the exam hall. The system operates by having each student scan their finger while the system cross-check the fingerprint database that was captured during registration to verify if the print is there. The system then grants access by displaying accepted without alarm and if not it sounds an alarm indicating an intruder and displays declined. The system will not be connected to a computer system or laptop. It would be a standalone, handheld and rechargeable device.

The hardware components involved in this project are

1. Arduino MEGA

2. Adafruit Fingerprint sensor 
3. HC-05 Bluetooth module

4. Power supply

5. Vero board and other materials for casing design.

Arduino microcontroller acts as the link between the fingerprint module and the Bluetooth module. It converts the data received from the Fingerprint Sensor (FPS) to a string that can be sent over the Bluetooth. It also parses the data received from the PC and sends appropriate commands to the FPS. It was used since it has multiple serial ports available on the board. This makes it easy to communicate with both Bluetooth module and FPS.

\section{Working Principle}

It is divided into two stages. They include the:

I. Enrollment

II. Verification

\section{Enrollment}

The device comes on when it is powered. When an individual is to be registered, a number is assigned to him/her using the keypad. This number assigned is automatically stored in the EEPROM of the ATMEGA IC used. When the individual places his/her hand on the finger print module, it captures the print and transfers it into the EEPROM and later stores in the memory card. This process is repeated to be stored in the memory of ATMEGA IC for confirmation. All the activity performed by the microcontroller is being displayed on the liquid crystal display $(\mathrm{LCD})$.

Verification:

The system verifies the student by scanning the fingerprint and compares with the ATMEGA captured image. If the image is registered, it prints out the individual's identification number to confirm his eligibility.

When a wrong finger is placed on the module, it scans the image, sends it to the ATMEGA. This browses through the images in its memory and if nothing is found, it prints out a message stating that the person in question has no personal details in its memory. A message "NOT REGISTERED" is displayed on the screen. Figure 1 and 2 depict the flowchart of the enrollment and verification stage.

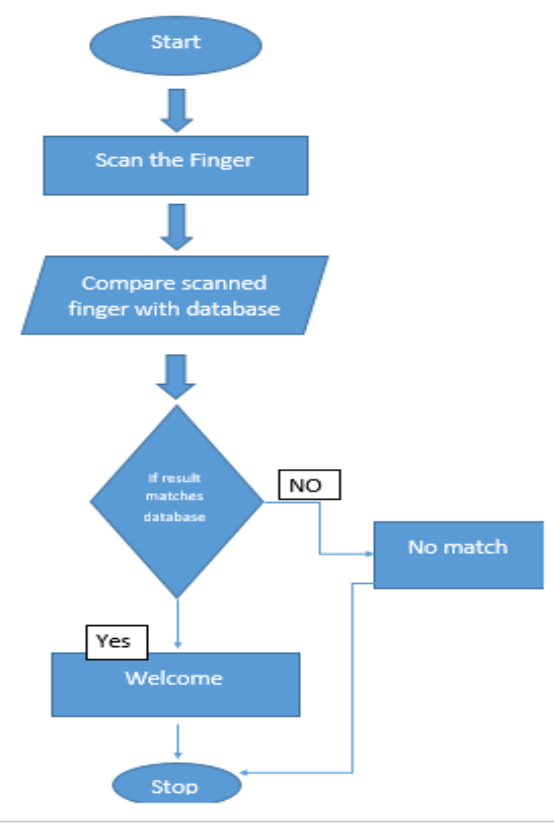

Figure 1: Flowchart for the enrollment stage 


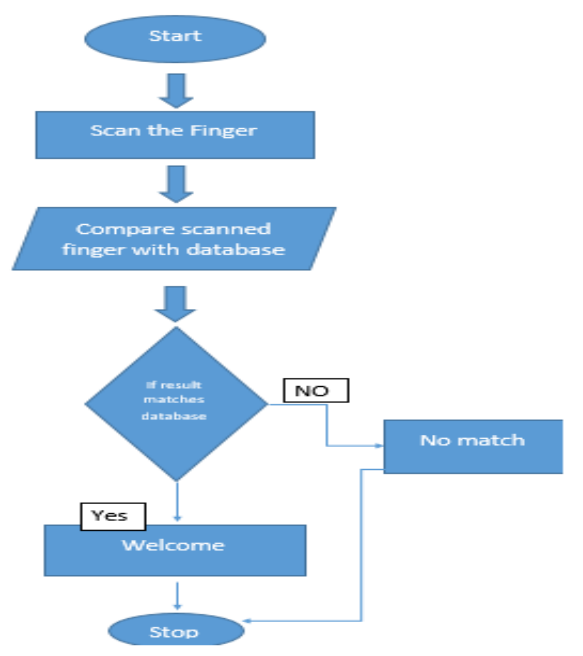

Figure 2: Flowchart for the verification stage

\section{Hardware Design of the System}

Basically, the system design can be divided into two main parts. First part of the system design is integration of microcontroller, liquid crystal display (LCD), keypad and fingerprint scanner. These four devices are important to capture the image of fingerprint, store the fingerprint information and display the information on the LCD. The second part of the system design is integration of microcontroller and Arduino data logging shield. The Arduino data logging shield is used to collect the student's information in real time and save it into the memory card. The memory card is removable.

The integration between hardware and software components are important to make sure the system works properly as planned. Figure 3 illustrate the system block diagram and figure 4 depict the circuit diagram of the system. In order to make the system portable, the Arduino MEGA microcontroller along with the fingerprint scanner and Arduino data logging shield are powered by a portable power source.

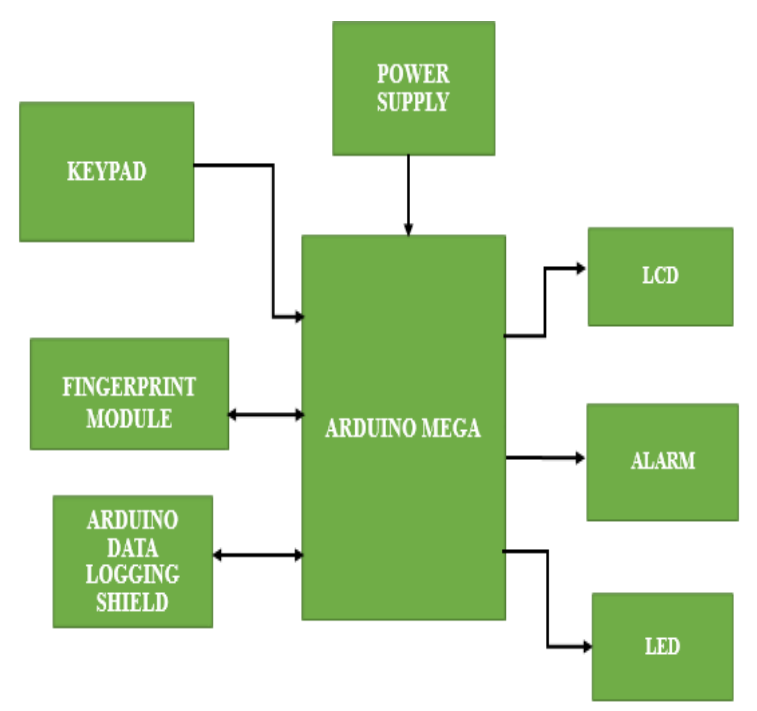

Figure 3: Block diagram of the system. 


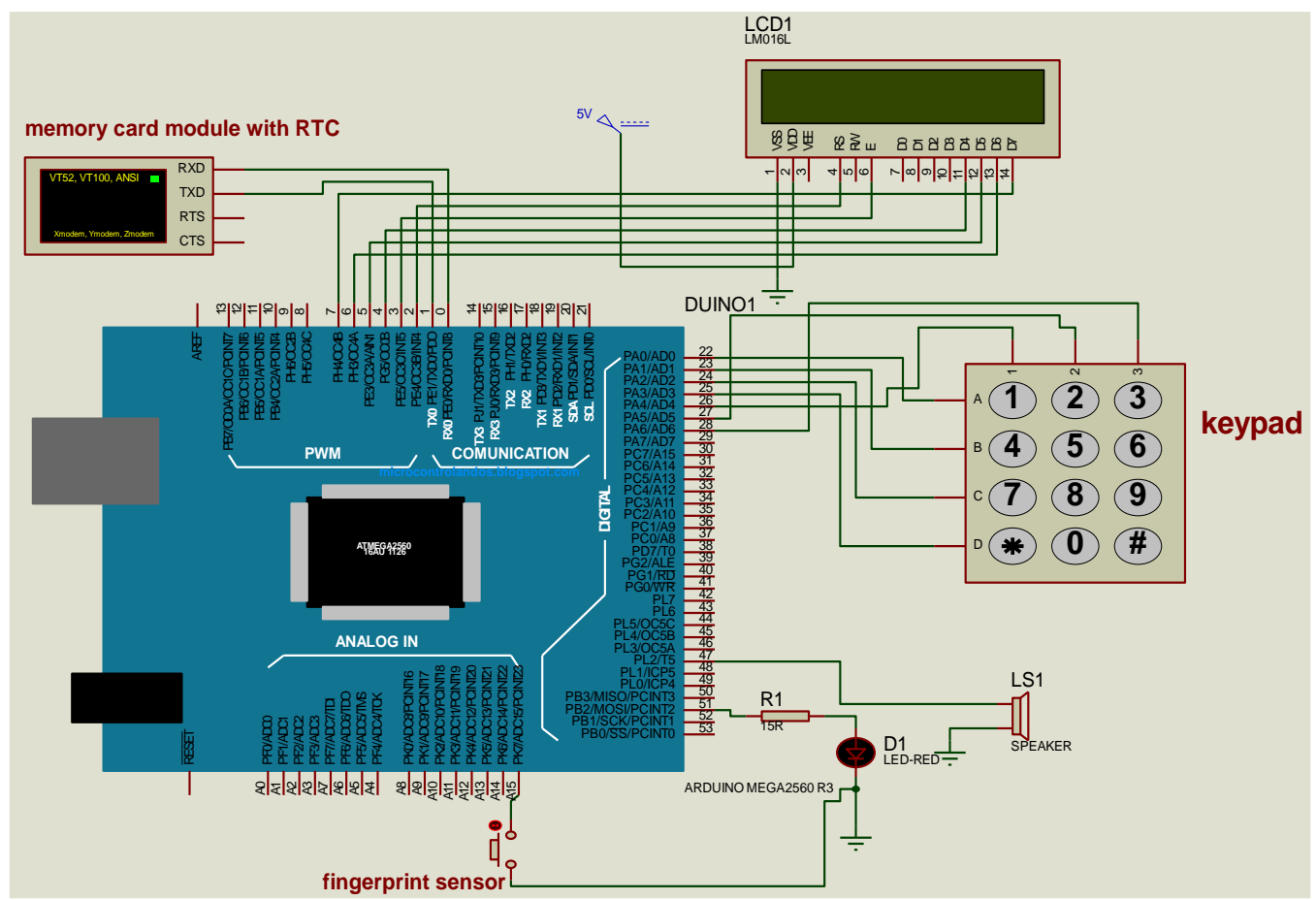

Figure 4: Circuit Diagram of the System

\section{Casing and Boxing}

After soldering all the components on the Vero board, the components were packed into a case as shown in Figure 5. The casing material used was a plastic material specially designed to have perforations for proper ventilation.

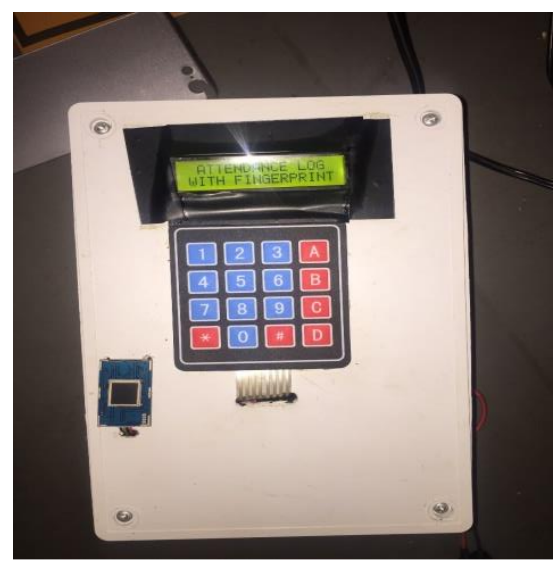

Figure 5: Casing and Boxing of the System

\section{Results and Discussion}

The system was tested with thirty-six (36) understudy fingerprints. The understudies were enrolled and registered with the system. Each understudy was given an ID and the system was able to verify that they were registered. Also, the system was able to identify an unregistered understudy and sounds an alarm. The reports generated with time-stamps are stored in the memory and the lecturer can use it as attendance. For security purpose, the system is password protected so that unauthorized person/persons will not be able to access the system to alter anything. 


\section{Conclusions}

The system successfully identified and verified the registered understudy fingerprint and stored the verified understudy so that the lecturer can retrieve the list of all understudies that was verified to take an examination. The system gives the time when the understudy was verified. In other words, the system generates a report in real time using the understudy fingerprint to avoid or prevent impersonation. Further research can be carried out to have more than one biometric technique like a fingerprint and facial recognition and also in very large scale organization, that the memory card cannot contain all the data. A hard-drive can be used.

\section{Conflicts of Interest}

Authors have declared that no competing interests exist.

\section{Funding Statement}

No Sponsor.

\section{References}

1) Eze Peter U, J. U. (2013). Bbiometric based Attendance System with Remote Real-time Monitoring for Tertiary institutions in developing Countries. IEEE.

2) Ezema L.S, C.-U. J. (2015). FINGERPRINT BASED ATTENDANCE MANAGEMENT SYSTEM. International Journal of Science\& Engineering Research, 1623.

3) Neeraj Kamboj1, V. R. (2015). Design \& Implementation of Fingerprint Biometrics based on Discretized Fingerprint Texture Descriptor. International Journal of Innovative Research in Computer and Communication Engineering, 3(6), 5466-5468.

4) Olaniyi, O. A. (2012). Lecture Attendance System Using Rado Frequency Identification and Facial Recognition. Computing, information System \& Development informatics Journal, 3(2), 36-40.

5) Tiwari, T. (2015). Biometrics based user authentication. American Journal of Engineering Research, 4(10), 148-159.

6) Kokumo. (2010). Lecture Attendance System Using Biometric Fingerprint. B.Tech Dissertation, Bells University of Technology, Department of Computer Science and Tecnology, Ota, Nigeria.

7) Jain, A. K. (2008, 6 4). Biometric authentication. Scholarpedia, 3(6), 3716 doi:10.4249/scholarpedia.3716.

8) Paul, R., Alane, K. and Ari, S. (2004). Biometric Technologies: Security, Legal and Policy Implications. USA: Center for Democracy and Technology and the Heritage Foundation. Rufai, M. M., Adigun, J. O. and Yekini, N. A. (2012). A Biometric Model for Examination Screening and Attendance Monitoring in Yaba College of Technology. World of Computer Science and Information Technology Journal (WCSIT). ISSN: 2221-0741, 2(4), pp. 120-124.

9) Hambali, M. A \& Jimoh R. G (2015). Performance Evaluation of Principal Component Analysis and Independent Component Analysis Algorithms for Facial Recognition. Journal of Advances in ScientificResearch \& Its Application (JASRA), 2, pp. $47-62$.

10) Maltoni, D., K. Jain, A. and Prabhakar, S., (2009). Handbook of Fingerprint Recognition. Second edn. London. Springer.

11) Mohammed Alhothaily, M. A.-K. (2015). Fingerprint Attendance System for Educational Institutes. Journal of Science \& Technology, 20(1), 34-44. doi:10.20428.

12) Mohd. $(2009,066)$. Class attendance system using active RFID. A Review.FKEE Compilation of papers. 